\title{
Phytochemical And Antimicrobial Studies On Moringa Oleifera Leaves Extracts.
}

\author{
Ojeaga Imohiosen, Haruna H. Gurama and Tajudeen B. Lamidi \\ Department of Science Laboratory Technology, Federal Polytechnic Bali, Taraba State, Nigeria
}

\begin{abstract}
The antimicrobial and medicinal properties of Moringa leaf extracts was examined through Phytochemical screening on the solvent extract and conducting bioassay on the target microorganisms: E. coli and Salmonella. The phytochemical screening of the plants constituents were assessed by using qualitative methods. Tests were conducted for the presence of the following active components: alkaloid, tannins, phlobatannins, phenol, flavonoids, glycoside, saponins, volatile oil, hydrolysable tannin and protein. All were present. The ethanol extract of the leaf was active against E. coli and salmonella measuring clear zones of inhibition $3.0 \mathrm{~mm}$ and $14.0 \mathrm{~mm}$ respectively. This indicate the presence of these bioactive components in Moringa, which proves its potency in the treatment of some bacterial infections
\end{abstract}

Keywords: Moringa Oleifera, Phytochemical sceening, Antimicrobial properties, microorganisms, Ethanol Extract.

\section{Introduction}

The world would be in a terrible state of health in the absence of chemotherapeutic drugs whose origin has been traced directly or indirectly to medicinal plants. A good number of plants with chemotherapeutic and antimicrobial properties are still being discovered, research upon and tested for different applications in the treatment of different ailments (Sofowora, 1982). Most of the drugs used in modern day Orthodox medicine were originally extracted from plant sources (roots, leaves, barks and seeds) examples include aspirin and quinine (Moore and Winston, 1996).

\subsection{Phytochemical}

Phytochemicals are chemical compounds that occur naturally in plants. The term is generally used to refer to those chemicals that may affect health, but are not established essential nutrients- proteins, carbohydrates, fats, minerals and vitamins (Liu, 2004). Phytochemicals have been used as drugs for millennia. For example, Hippocrates may have prescribed willow tree leaves to abate fever. There is also abundant scientific and government support for recommending diets rich in nutrients from fruits and vegetables, there is only limited evidence that physiological effects result from any specific Phytochemical (US Department of Health and Human Services, 2010). According to Kumar and Singh (1976), phytochemicals are secondary metabolites and are often found in disposable parts of plants. These include stems, roots, barks, leaves, flowers, fruits and seeds. Common phytochemicals found in plants include tannins, phlobatannins, quinines, alkaloids, saponins, flavonoids, steroids, terpenoids, cardiac glycosides, sugar etc.

\section{Quinones}

Quinones is a generic for a class of cyclic organic compounds containing two carbonyl groups either adjacent or separated by a vinylene group - $\mathrm{CH}=\mathrm{CH}-$ in a usual six-membered unsaturated ring. Hydroquinone is known principally as a photographic developing agent. Quinones are found in bacteria, certain plants and in only few animals. Quinones may be used as indicators of acidity or alkalinity and in various dyes used to colour certain types of fabrics.

\begin{abstract}
Alkaloids
Alkaloids comprise the largest single class of secondary substances that are known to number over 2000. Alkaloids are basic substances, which contain one or more nitrogen atom(s) in a ring and because of their toxic effects and dramatic physiological activities; they are widely employed in medicine. Alkaloids have marked effect on the central nervous system; examples include cocaine, caffeine, nicotein, bellodna and coceanite. The antimalaria drug, quinine, obtained from the bark of cinchona plant is another example of an alkaloid.
\end{abstract}

\section{Tannins}

The term tannins, was introduced in 1796 to describe a group of compounds in some plants and used in the production of leather. Tannins were widely distributed in plants and many occur as glycosides. One of the 
best sources of tannin is Nutgall. Tannins are coloured, non crystalline substances, which form colloidal solutions in water. Tannins are used in the industry for tanning hides.

Phlobatannins are responsible for the red colour of several drugs containing these phlobatannins and their breakdown products. Catechin and flavonoids polymerize in acid to yield red amorphous compounds called phlobatannins.

\section{Saponins}

Saponins may occur as glycosides of triterpenes with soap-like properties and are detected by their ability to foam persistently and to lyses red blood cells. Saponins are highly toxic which diffused into the blood stream when taken orally, they are comparatively harmless. They are characterized by the presence of a steroidal side chain. Plant steroidal saprogenic are used as starting raw materials in the synthesis of steroidal drugs like corticosteroids, sex hormones and oral contraceptives of saprogenic family, examples are tigogenin and digitogenin.

\section{Flavonoids}

Flavonoids also collectively known as vitamin P and citrin (found to be eriodictyol), are a class of plant secondary metabolites or yellow pigments having a structure to that of flavones. Flavonoids (specifically flavonoids such as the catechins) are the most common group of polyphenolic compounds in the human diet and are found ubiquitously in plant. Flavonols, the origin bio-flavonoids such as quercetin, are also found ubiquitously, but in lesser quantities (Wikipedia, 2013).

\section{Steroids}

Steroids are a large group of naturally occurring and synthetic lipids, or fat-soluble chemical, with a great diversity of physiological activity. Synthetic steroids are well known for their use by athletes as a performance-enhancing drug. The many different steroids include certain alcohols (sterols), bile acids, hormones, plant compounds, and the poisons found in the skin of some toads. Various sterols found in the skin of human beings are transformed into vitamin $\mathrm{D}$ when they are exposed to the ultraviolet rays of the sun. Cholesterol, a major contributor to arteriosclerosis, is a sterol. Steroid hormones, which are similar but not identical to sterols, include the adrenal cortical steroids hydrocortisone, cortisone, aldosterone, and progesterone; and the female and male sex hormones.

\section{Glycoside}

A glycoside is a molecule in which sugar is bound to a non carbohydrate moiety, usually a small organic molecule. Glycosides play numerous important roles in living organisms like fungi, bacteria and moots. Many plants store chemicals in the form of inactive glycosides. These can be activated by enzymes' hydrolysis, which causes the sugar parts to be broken off making the chemical available for use. Many of such glycosides are used for medications. In animals and humans, poisons are often bound to sugar molecules as part of their elimination from the body. The sugar group is known as glycone and the non sugar as aglycone or genin part of the glycoside.

\subsection{Moringa plant}

Moringa is the sole genus in the flowering plant family Moringaceae. The name is derived from the Tamil word murunggai or the Malayalam word muringa, both of which refer to Moringa oleifera. It contains 13 species from tropical and sub tropical climates that range in size from tiny herbs to massive trees. The most widely known species is Moringa oleifera, a multi-purpose tree native to the foothills of the Himalayas in northwestern India and cultivated throughout the tropics. M. stenopetala, an African species, is also widely grown, but to a much lesser extent than M. oleifera (United States Department of Agriculture, 1996).

Moringa oleifera silviculture is currently being promoted as a means to combat poverty and malnutrition. It grows quickly in many types of environments, and much of the plant is edible for man and livestock. The leaves contain all essential amino acid and are rich in protein, vitamin A, vitamin B, vitamin $\mathrm{C}$, and minerals. Feeding the high protein leaves to cattle has been shown to increase weight gain by up to $32 \%$ and milk production by $43 \%$ to $65 \%$. The seeds contain $30 \%$ to $40 \%$ oil that is high in oleic acid, while degreased meal is $61 \%$ protein. The defatted meal is a flocculants and can be used in water purification to settle out sediments and undesirable organisms (Schill and Susanne Retka, 2008).

\section{Botany of Moringa Oleifera}

The plant Moringa Oleifera is a native of the India sub-continent and naturalized in tropical and subtropical areas in the world. It belongs to the family moringacae and it is deciduous tree or shrub, fast growing, drought resistance average height of 12 meters at maturity. This plant has twelve other varieties of species and 
they are as follows: Moringa arborea, Moringa borziana, Moringa concanensis, Moringa drouhardii, Moringa hildebrandtii,Moringa longituba, Moringa ovalifolia, Moringa peregrina, Moringa pygmaea, Moringa rivae, Moringa ruspoliana, and Moringa stenoprtala._The classification of Moringa oleifera is stated below.

\author{
Classification \\ Kingdom: plantea \\ Sub kingdom: Tracheobionta \\ Super Division: Spermatophyta \\ Division: Magnoliophyta \\ Class: Magnoliopsida \\ Subclass: Dilleniidae \\ Order: Capparales \\ Family: Moringaceae \\ Genus: Moringa \\ Species: Oleifera
}

\title{
Origin And Habitat
}

Moringa oleifera, an important medicinal plant is one of the most widely cultivated species of the family Moringeneric the moringaceae, that is native to the sub-himalayan tracts of india, Pakistan, Bangladesh and Afghanistan. The rapidly grown tree (also known as Ben oil tree,horseradish tree, drumstick tree benzolive tree, kelor, marango, mlonge, moonga) was utilized by the ancient Romans, Greeks and Egyptain. It is highly valued from time immemorial because of its vast medicinal properties. It is now widely cultivated and has become naturalized in many location in the tropics. (James A. Duke. 1983).

\section{Description}

Moringa oleifera is a short, slender, deciduous, perennial tree, grows to about $10 \mathrm{~m}$ tall, rather slender with drooping branches; branches and stem are brittle, with corky bark; leaves are feathery, pale green, tripinnate compound leaf (Dutta A.C. 2008), (30-60 cm long), with many small leaflets, 1.3-2 cm long, 0.6-0.3 $\mathrm{cm}$ wide, lateral ones somewhat elliptic, terminal ones obovate and slightly larger than the lateral ones; flowers are fragrant, white or creamy-white, $(2.5 \mathrm{~cm}$ in diameter), borne in sprays, with five $(5)$ at the top of the flower; stamens are yellow; pods are pendulous, brown, triangular, splitting lengthwise into 3 parts when dry, (30-120 $\mathrm{cm}$ long, $1.8 \mathrm{~cm}$ wide), containing about 20 seeds embedded in the pith. The pod is tapering at both ends, nine (9) ribbed; seeds are dark brown, with 3 papery wings (James A. Duke. 1983).

\section{Medicinal Uses and Properties of Moringa}

According to Hartwell (1967-1971), the flowers, leaves and roots are used in folk remedies for tumors, the seed for abdominal tumors. The root decoction is used in Nicaragua for dropsy. Root juice is applied externally as rubefacient or counter irritant. Leaves applied as poultice to sores, rubbed on the temples for headaches, and said to have purgative properties. Bark, leaves and roots are acrid and pungent, and are taken to promote digestion. Oil is somewhat dangerous if taken internally, but is applied externally for skin diseases. Bark regarded as antiascorbic, and exudes a reddish gum with properties of tragacanth; sometimes used for diarrhea. Roots are bitter, act as a tonic to the body and lungs, and are emmenagogue, mild diuretic and stimulant in paralytic affliction, epilepsy and hysteria.

Phytochemical studies have identified substances present in various parts of Moringa that have proven effective against hypertension and high cholesterol, while its antibacterial, antifungal and antioxidant properties are already well known to practitioners of both traditional and modern medicine. The functioning of nearly every physical system within the body can be enhanced or improved in some ways by the chemicals present within the plant.

\section{Antimicrobial Activity of Moringa}

The antimicrobial activities of Moringa Oleifera leaves, roots, barks, and seeds were investigated in vitro against bacteria, yeast, dermatophytes and helminthes pathogenic to man. By a disk-diffusion method, it was demonstrated that the fresh leaf juice and aqueous extract from the seeds inhibit the growth of Pseudomonas aeruginosa and Staphylococcus aureus and that extraction temperatures above $56^{\circ} \mathrm{C}$ inhibit this activity (Caceres, 1991).

Antimicrobial is the act of killing or inhibiting or suppressing microorganism from their multiplication or growth. These are chemical substances secreted by microorganisms, or derived from plants or synthesized in the laboratory which in certain concentration inhibit the growth, multiplication or metabolism of microorganism (Blood, 1990).Most of the antimicrobial agents fall into broad structure and so the classification scheme for all 
antimicrobial agents has proven difficult. The following system of classification was adopted based on the type of organism acted upon. Based on their primary activity they are specially known as antibacterial, antifungal, antiviral, antiprotozoan and antihelmintic agents (George, 1983). There are some chemicals that are known to have anti-bacterial properties which includes; flavonoids and alkaloids. Most of these phytochemical constituents are potent bioactive compounds found in medicinal plant, parts of which are precursors for the synthesis of useful drug (sofowora, 1993).

\subsection{Escherichia coli}

Escherichia coli is a Gram-negative, facultative anaerobic, non-sporulating, rod-shaped bacterium that is commonly found in the lower intestine of warm-blooded organisms (endotherms). Most E.coli strains are harmless, but some serotypes can cause serious food poisoning in humans, and are occasionally responsible for product recalls. The harmless strains are part of the normal flora of the gut, and can be benefit to their hosts by producing vitamin $\mathrm{K}$, and by preventing the establishment of pathogenic bacteria within the intestine. E.coli uses mixed-acid fermentation in anaerobic conditions, producing lactate, succinate, ethanol, acetate and carbon dioxide. Since many pathways in mixed-acid fermentation produce hydrogen gas, these pathways require the levels of hydrogen to be low, as is in the case when E.coli lives together with hydrogen consuming organisms, such as methanogens or sulphate-reducing bacteria.

Optimal growth of E.coli occurs at $37^{0} \mathrm{C}\left(98.6^{\circ} \mathrm{F}\right)$ but some laboratory strains can multiply at temperature of up to $49^{\circ} \mathrm{C}\left(120.2^{\circ} \mathrm{F}\right)$. Growth can be driven by aerobic or anaerobic respiration, using a large variety of redox pairs. Symptoms depend largely on the virulence of the infecting E.coli strain. They range from vomiting and a few loose bowel movements, to profuse watery diarrhea, to severe cramps and bloody diarrhea. Fever is not usually prominent and recovery usually occurs within 10 days. Hemolytic uremic syndrome however develops after some bloody diarrhea case(Wikipedia,2013)

\subsection{Salmonella}

Salmonella is a genus of rod-shaped, Gram-negative, non-spore-forming, predominantly motile enterobacteria with diameters around 0.7 to $1.5 \mu \mathrm{m}$, lengths from 2 to $5 \mu \mathrm{m}$, and flagella that grade in all directions (i.e., peritrichous). They are chemoorganotrophs, obtaining their energy from oxidation and reduction reactions using organic sources, and are facultative anaerobes. Most species produce hydrogen sulfide which can readily be detected by growing them on media containing ferrous sulfate, such as TSI. Most isolates exist in two phases: a motile phase I and a non motile phase II. Cultures that are non motile upon primary culture may be switched to the motile phase using a Cragie tube (Clark and Barret, 1987).

Salmonella is closely related to the Escherichia genus and are found worldwide in cold- and warmblooded animals (including humans), and in the environment. They cause illnesses such as typhoid fever, paratyphoid fever, and foodborne illness (Ryan and Ray, 2004). Salmonellosis is a disease caused by raw or undercooked food. Infection usually occurs when a person ingests foods that contain a high concentration of the bacteria, similar to a culture medium. In otherwise healthy adults, the symptoms are usually mild. Normally, no

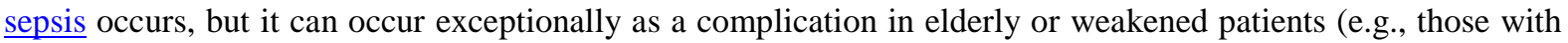
Hodgkin's disease).Salmonella bacteria can survive for weeks outside a living body, and they are not destroyed by freezing (Sorrells, 1970). Ultraviolet radiation and heat accelerate their demise; they perish after being heated to $55^{\circ} \mathrm{C}\left(131^{\circ} \mathrm{F}\right)$ for $90 \mathrm{~min}$, or to $60^{\circ} \mathrm{C}\left(140^{\circ} \mathrm{F}\right)$ for $12 \mathrm{~min}$ (Beuchat and Heaton, 1975). To protect against Salmonella infection, heating food for at least ten minutes at $75^{\circ} \mathrm{C}\left(167{ }^{\circ} \mathrm{F}\right)$ is recommended, so the centre of the food reaches this temperature (USDA).

Most people with salmonellosis develop diarrhoea, fever, vomiting, and abdominal cramps 12 to 72 hours after infection. In most cases, the illness lasts four to seven days, and most people recover without treatment. In some cases, though, the diarrhea may be so severe, the patient becomes dangerously dehydrated and must be taken to a hospital. At the hospital, the patient may receive intravenous fluids to treat the dehydration, and may be given medications to provide symptomatic relief, such as fever reduction. In severe cases, the Salmonella infection may spread from the intestines to the blood stream, and then to other body sites, and can cause death, unless the person is treated promptly with antibiotics. The elderly, infants, and those with impaired immune systems are more likely to develop severe illness.

\subsection{Collection and identification of Moringa oleifera}

\section{Materials And Methods}

Fresh samples of the leaves of Moringa oleifera were collected in the month of September from Bali, Taraba State, Nigeria. It was then taken to the Department of Science Laboratory Technology, Federal Polytechnic Bali for identification. The sample were air-dried and pounded into powder, using pestle and mortar. 


\subsection{Extraction}

The powdered sample were subjected to sohxlet extraction using ethanol, the filtrate were evaporated in an oven at $50^{\circ} \mathrm{C}$.

\subsection{Preparation of Laboratory Reagents for Phytochemical Analysis}

1. Wagner's Reagent: $2 \mathrm{~g}$ of iodine crystals and $3 \mathrm{~g}$ of potassium iodide were dissolved in $100 \mathrm{~cm}^{3}$ of distilled water and properly stirred to homogenize into a solution of Wagner's reagent.

2. Ferric Chloride Solution: $5 \mathrm{~cm}^{3}$ of ferric chloride (Iron III Chloride) was dissolved in $50 \mathrm{~cm}^{3}$ of distilled water to form a homogenous solution of ferric chloride.

3. Dilute solution of Hydrochloric Acid: $2 \mathrm{~cm}^{3}$ of hydrochloric acid was measured out using measuring cylinder and poured into a $250 \mathrm{~cm}^{3}$ beaker containing distilled water and stirred to form a homogenous dilute solution of $\mathrm{HCl}$.

\subsection{Phytochemical Screening}

The phytochemical screening of the plants constituents were assessed by using qualitative methods described by Trease and Evans, 1989. Test were conducted for the presence of the following active components; anthroquinnes, alkaloid, terpenoids, flavonoids, cardiac glycoside and saponins. Results as shown in table I

\section{Procedure for Phytochemical Analysis}

1. Alkaloid Test: Equal volumes of the solvent extract $\left(5 \mathrm{~cm}^{3}\right)$ and the Wagner's reagent were placed into a clean test tube and observed for some minutes. The presence of alkaloid was indicated by a brown precipitate.

2. Phenol: $2 \mathrm{ml}$ of extract was added to $2 \mathrm{mls}$ of ferric chloride solution $(\mathrm{FeCl})$, a deep bluish green solution is formed with presence of phenols.

3. Phlobatannins: $1 \mathrm{~cm}^{3}$ of hydrochloride acid and $1 \mathrm{~cm}^{3}$ of solvent extract were placed into a clean test tube and the tube was heated for about 10 minutes. Reddish green coloration indicates the presence of phlobatannins.

4.Flavonoids: $5 \mathrm{~cm}^{3}$ of the solvent extracts was placed into a test tube and few pieces of magnesium chips were added, followed by concentrated hydrochloric acid in drops And then in excess. Reddish colouration indicates the presence of flavonoids.

5. Glycosides: $25 \mathrm{ml}$ of dilute sulphuric acid was added to $5 \mathrm{ml}$ of the extract in a test tube and boiled for 15 minutes, cooled and neutralized with $10 \% \mathrm{NaOH}$, and then $5 \mathrm{ml}$ of Fehling solution A and B was added. A brick red precipitate of reducing sugar indicates the presence of glycosides.

6. Saponins (Froth test): $1 \mathrm{~g}$ of the sample was weighed into a conical flask in $10 \mathrm{ml}$ of sterile distilled water was added and boiled for $5 \mathrm{~min}$. The mixture was filtered and $2.5 \mathrm{ml}$ of the filtrate was added to $10 \mathrm{ml}$ of sterile distilled water in atest tube. The test tube was stopped and shaken vigorously for about 30 second. It was then allowed to stand for half an hour. Honeycomb froth indicated the presence of saponins.

7. Volatile oils: $2.0 \mathrm{ml}$ of extract solution was shaken with $0.1 \mathrm{ml}$ dilute sodiumhydroxide and a small quantity of dilute $\mathrm{HCl}$. A white precipitate was formed with volatile oils.

8. Hydrolysable tannins: $4 \mathrm{ml}$ of the extract was shaken in a test tube, after which $4 \mathrm{ml}$ of $10 \%$ ammonia solution was added. Formation of an emulsion on shaking indicated the presence of hydrolysable tannins.

9.Tannin: $3 \mathrm{~g}$ of the powdered sample was boiled in $50 \mathrm{ml}$ distilled water for 3 minutes on a hot plate. The mixture was filtered and a portion of the filtrate diluted with sterile distilled water in a ratio of 1:4 and 3 drop of $10 \%$ ferric chloride solution added. A blue or green colour indicates the presence of tannins.

10.Protein: $1 \mathrm{ml}$ of extract was shaken with about $2 \mathrm{ml}$ of million's reagent. A brick-red colouration indicated the presence of protein.

\subsection{Microorganisms}

The microorganisms used include E. coli and salmonella. All the organisms' strains were obtained from the microbiology department of Sancta maria clinic, Bali

\subsection{Antimicrobial Activity Test}

The agar-gel diffusion method described by Younmans, G. P., (1967) and Zaria L.T. (1955) was adopted for the antimicrobial sensitivity test. The stock was maintained on nutrient agar slant and subculture in the nutrient broth for incubation at $37^{\circ} \mathrm{C}$. The organisms were aseptically introduced and evenly spread using sterile inoculation wire loop on the surface of the sterile agar slant. The extract was introduced into the wells in the plates. The plates were incubated at $37^{\circ} \mathrm{C}$ for 24 hours; zones of inhibition were recorded in millimeters. 
Tables and Result

\section{Results And Discussion}

\section{Table I: Chemical constituents of ethanol leaf extracts of Moringa Oleifera}

\begin{tabular}{|l|l|l|l|}
\hline S/N & Chemical Constituent & Test & Confirmation \\
\hline 1 & Alkaloids & Wagner's & + \\
\hline 2 & Tannins & Ferric Chloride & + \\
\hline 3 & Phlobatannins & Hydrochloric Acid & + \\
\hline 4 & Phenol & Ferric Chloride & + \\
\hline 5 & Flavonoids & Magnesium Chips & + \\
\hline 6 & Glycosides & Fehling's & + \\
\hline 7 & Saponins & Emulsifying & + \\
\hline 8 & Volatile Oils & Sodium Hydroxide & + \\
\hline 9 & Hydrolysable Tannins & Ammonia & + \\
\hline 10 & Protein & Millions & + \\
\hline
\end{tabular}

$+=$ Positive, $\quad-=$ Negative,

The results as presented in Table I; the phytochemical screening conducted on ethanol leaf extract of Moringa oleifera revealed the presence of some bioactive components such as alkaloids, tannins, phlobatannins, phenol, flavonoids, glycosides, saponins, volatile oil, hydrolysable tannins, protein. The presence of some of these bioactive components confirms similar research conducted by Dahiru, D., Onubiyi, J. A. and Umaru, H. A.(2006) , while the result obtained showed the presence of alkaloids, glycosides, phenols, saponins, tannins, volatile oils and hydrolysable tannins.

Table II: antimicrobial activity of ethanol leaf extracts of Moringa Oleifera showing zones of inhibition

\begin{tabular}{|l|l|l|}
\hline S/N & Micro organism & Zones of Inhibition \\
\hline 1. & Salmonella & $14.0 \mathrm{~mm}$ \\
\hline 2. & E. coli & $3.0 \mathrm{~mm}$ \\
\hline
\end{tabular}

$\mathrm{mm}=$ millimeter

Table II, shows the effects of the ethanol extract on some microorganisms the degree of effectiveness of the extract on the test organisms is directly proportional zones of inhibition on both E.coli and salmonella measuring $3.0 \mathrm{~mm}$ and $14.0 \mathrm{~mm}$ respectively.

\section{Conclusion And Recommendation}

The leaf of Moringa Oleifera has shown the presence of some bioactive components which possesses activity against some microorganisms This, therefore justifies the traditional use of Moringa oleifera leaf against some ailments by traditional healers. However, the required dosage and purification remains a challenge. Hence I recommended that further research should be carried out on the dosage and in vivo evaluation of the leaf extract.

\section{Reference}

[1]. Sofowora, A. (1982): Medicinal Plants and Traditional Medicine in Africa. John Willey and Sons Ltd., New York. Pp 128-129, $142-159$.

[2]. Moore, W. R. and Winston, A. (1996): Laboratory Manual for Organic Chemistry. A Microscale Approach. The McGraw-Hill Company, New York. Pp 53-68,197.

[3]. U S Department of Health and Human Services (2010):

[4]. Kumar, H. D. and Singh, H. N. (1976): Plant Metabolism. Affiliated East West Press Private Ltd, India, Pp $246-271$.

[5]. Neste, E. W. (2004): Microbiology; A Perspective. $4^{\text {th }}$ ed. The McGram-Hill Companies, Inc. New York. Pp 537-540, 694-695, 614-616.

[6]. George, M. S. (1981): Antimicrobial Agents; Encyclopedia of Science and Technology. $6^{\text {th }}$ ed. McGraw-Hill, NewYork. Pp 644

[7]. Blood, D. C. and Students (1990): Baillure's Comprehensive Veterinary Dictionary. $2^{\text {nd }}$ ed. Clays Ltd, England. Pp 59.

[8]. Liu, R. H. (2004): Potential Synergy of Phytochemicals in Cancer Prevention Mechanism of Action. The Journal of Nutrition. 134(12 Suppl.); 34795-34855.

[9]. Trease, G. E. and Evans, W. C. (1989). Pharmacognsy. $11^{\text {th }}$ ed. Brailliar Tiridel Can. Macmillian publishers.

[10]. United States Department of Agriculture (1996-09-17). Retrieved 2011-09-26.

[11]. Schill, Susanne Retka (2008-05-14). Multidimensional Moringa. Biodiesel magazine. Retrieved 2011-09-26.

[12]. Hartwell, J. L. (1967-1971). Plants used against Cancer. A survey. Lloydia 30-34.

[13]. http://en.wikipedia.org/wiki/antimicrobial-properties-of-copper.

[14]. Clark MA, Barret EL (June 1987). "The pHs gene and hydrogen sulfide production by Salmonella typhimurium.". J Bacteriology 169 (6): 2391-2397.

[15]. Ryan KJ, Ray CG (editors) (2004). Sherris Medical Microbiology (4th Ed.). McGraw Hill. pp. 362-8. ISBN 0-8385-8529-9.

[16]. Sorrells, K.M.; M. L. Speck and J. A. Warren (January 1970). "Pathogenicity of Salmonella gallinarum After Metabolic Injury by Freezing". Applied and Environmental Microbiology 19 (1): 39-43. PMC 376605. PMID 5461164.

[17]. Retrieved 2010-08-19. "Mortality differences between wholly uninjured and predominantly injured populations were small and consistent (5\% level) with a hypothesis of no difference."

[18]. Beuchat, L. R.; E. K. Heaton (June 1975). "Salmonella Survival on Pecans as Influenced by Processing and Storage Conditions". Applied and Environmental Microbiology 29(6): 795-801. PMC 187082. $\underline{\text { PMID } 1098573 . ~ R e t r i e v e d ~ 2010-08-19 . ~ " L i t t l e ~}$ decrease in viable populationof the three species was noted on inoculated pecan halves stored at $18,-7$, and $5^{\circ} \mathrm{C}$ for 32 weeks."

[19]. Partnership for Food Safety Education (PFSE) Fight BAC! Basic Brochure. 
[20]. USDA Internal Cooking Temperatures Chart. The USDA has other resources available at their $\underline{\text { Safe Food Handling fact-sheet }}$ page. See also the National Center for Home Food Preservation

[21]. Dahiru, D., Onubiyi, J. A. And Umaru, H. A. (2006).Phytochemical Screening and Antiulcerogenic Effect of Moringa Oleifera Aqueous Leaf Extract: Afr. J. Trad. CAM (2006) 3 (3): 70 - 75

[22]. James A. Duke. (1983): Handbook of Energy Crops. New York.

[23]. Dutta A.C. (2008): Batany for Degree Students, Sixth edition. Printed in India by Sai Printopack and published by Oxford University press. Pp 35 